\title{
Dispensing with formalities in art education research
}

Palmyre Pierroux

This article investigates how high school students master and appropriate concepts in aesthetics and modern art in art history classes and in art museums. It is argued that distinctions between schools and museums as places of formal and informal learning, respectively, are not useful analytical categories for understanding complex meaning making processes.

\section{BACKGROUND}

In recent years, the development of the new field of 'visual studies' has been discussed as infringing on the disciplinary borders of art history, aesthetics and art criticism (Holly and Moxey 2002; Bal 2003). This shift is linked to new media, and to changes in artistic activity, as understandings of art have increasingly broadened from autonomous object and private symbolic space to digital presence and 'events' situated in the realm of human interactions and cultural-historical practices (Mirzoeff 1999; Bourriaud 2002). One might assume that the significance of such a move toward an expanded field of art history would bring about similar upheavals in art education research. All the more noteworthy, then, is the extent to which art education research in schools and museums, on the whole, continues to revolve around traditional problems in aesthetics concerning what I will generalize as being essentialist and contextualist positions. Briefly stated from an educational standpoint, the former holds that meaning is intuitively derived from the unmediated, mainly perceptual experience of art objects, while contextualist positions stress that meaning is constructed through disciplinary knowledge associated with artworks. ${ }^{1}$ These deeply embedded, unresolved positions might explain why the concept of learning in art museums is unclear and operates, as Karen Knutson suggests, mostly as "implicit construct, institutionally, and occupationally defined" (2002:42).

The dichotomy between contextualism and essentialism is also rooted, I propose, in the distinction that research makes between learning about art in schools and in museums. Compulsory modern art history education, concerned with formal analysis and contextual information about artworks, is relegated to the domain of tutored, or what is generally referred to as formal learning (Paris and Ash 2000; Packer and Ballantyne 2002; Martin 2004). Art museums, on the other hand, are studied as sites of voluntary, informal learning 
that promote intrinsic motivation (Paris 1997), aesthetic development (Paris and Hapgood 2002), prolonged looking, explanatory engagement, and personal meaning making (Leinhardt and Knutson 2004) through encounters with authentic objects. Although $\mathrm{Pa}$ ris and Hapgood account for some of the problems posed by this analytical divide between school learning and informal learning environments (ILEs include museums, the home, and other kinds of non-school learning), they conclude that "learning based on objects and experiences rather than text, (is) perhaps (sic) the key distinction between traditional school and non-school learning" (2002: 41). In other words, museum research often operates with the premise that informal learning in art museums uses authentic objects and is based on experience (essentialism), while formal learning about art in schools uses reproductions and is based on texts (contextualism).

\section{RESEARCH QUESTIONS}

In this article, I challenge the premise that the distinction between formal and informal learning is a productive means of framing museum education research. Based on data gathered from observations of high school students in art history classes and on art museum tours, learning will instead be explored as a culturally situated activity that forms and is formed by social practices. This means that while acknowledging that the communities in which we act are historically and culturally developed, researching human understanding necessarily entails an interest in how meaning is achieved in situ. ${ }^{2}$

In adopting this stance, I aim to contribute to a growing body of museum research that draws on sociocultural theory to frame methodological investigations of museum learning, or what is more commonly referred to as meaning making activity (Ellenbogen 2003; Dierking et al. 2004). The use of meaning making as a learning concept reflects a research concern with how understanding develops and unfolds rather than with instruction or assessment (Allen 1998; Schauble et al. 1998). ${ }^{3}$ Meaning making is a particularly apt concept for experiences and encounters in modern and contemporary art museums, since undermining fixed understandings of art that may be 'learned' has been the larger project of artists for more than a century. In addition, this article presents a different approach to school field trip research, which has traditionally been concerned with curriculum and policy evaluation, cognitive outcomes, and behavioral patterns (Packer and Ballantyne 2002; Xanthoudaki 1998; Falk and Dierking 1997).

Specifically, the following research questions are posed: How do high school students construct meaning in encounters with modern art? What kinds of relationships exist between museum learning and school learning about art? What becomes art in the respective cultural practices of classroom and museum gallery? The article is organized in three parts. First, a brief account of the theoretical approach is given. In the second part of the article, transcribed segments of discourse selected from high school art education classes in Norway and the United States will be presented. The data will be then analyzed, compared across school and museum settings, and discussed in relation to the contrasts formal/informal and contextualism/essentialism in museum research. 
Sociocultural theory is a general term for a broad range of research within the human sciences that has developed over several generations and is based largely on the appropriation of ideas of the Russian psychologist Lev Vygotsky. Although concerns differ, several key concepts are shared. Central among these are Vygotsky's understanding of the social development of mind, and the essential mediating role that historical-cultural tools and signs such as language, particularly human speech, play in human development (Vygotsky 1978). A sociocultural approach in learning research thus differs from studying individual affective and cognitive learning behaviors. Rather, relationships are studied between human interactions and the cultural, institutional, and social situations in which they take place, making activity the unit of analysis (Wertsch 1998). In art education, we recognize such emphasis on human activity in the work of the Pragmatist John Dewey and his idea that all teaching and learning is conditional and contingent (Popkewitz 1998). In relation to aesthetics, these key concepts suggest that meaning - and art - may be understood and studied as actively constructed and negotiated through social processes (Pierroux in press).

What is the significance of sociocultural theory for the concepts formal/informal learning? In brief, a sociocultural perspective rejects the notion that institutions determine types of knowledge that are taught and learned, as this premise is unable to sufficiently and methodologically account for the complex, situated and negotiated nature of human activity. Take, for example, the above definition of informal learning in art museums, which implies opportunities to freely choose, reflect and experience aesthetically works of art. In research on school field trips, it has been found that such primary features of informal learning as free choice and enjoyment are not characteristic of students' experiences when visiting museums with their class. Rather, some research states that learning in museums is not considered enjoyable by many students simply because it is school-related; school trips are compulsory, often with a 'teacher-teller' guide, worksheets and individual assessment (Griffin 2004). Ostensibly, then, museums lose their status as sites of informal learning when school-related activity, such as planned objectives and tour guides, is involved (Grinder and McCoy 1985).

Yet, it may be argued, many art museum educators reject the notion of school tours as formal learning solely aimed at teaching art history. Along the same lines, many art teachers in schools also regard the teaching of modern and contemporary art history as more than the compulsory art survey. In other words, as some museum researchers have begun to acknowledge, distinctions between learning activities based solely on their location is not a fruitful analytical framework (Paris and Hapgood 2002, Martin 2004). In this article, such broad conceptions of learning are set aside in order to examine the discourse and activity of students studying modern and contemporary art in schools and museums.

\section{Method}

Access to high school modern art history classes and art museum tours was secured through contact with museum educators at Norwegian and North American art museums. The study is based on videotaped observations of five 
high school classes studying modern art history at two different schools, one in Norway and one in the United States. Although not a comparative study, there is a correspondence between the classes at these two schools in terms of disciplinary domain (abstract and non-figurative modern art history), average student age (15-17 years old), and class size (15-20 students). This correspondence, and the fact that all of the observed classes participated in a museum field trip, allowed for tracing similarities across the different learning situations. ${ }^{4}$

The methodological approach chosen for the study is interaction analysis, in which attention is paid to moment-to-moment verbal and non-verbal activity (Jordan and Henderson 1995). A single video camera was used to capture classroom and gallery activity, and teachers and museum educators also wore wireless microphones. The use of video recordings made it possible to capture participants' talk and orientation to each other, to artworks, and to other artifacts at a detailed level, and to allow repeated playback and scrutiny during analysis.

\section{SELECTION AND ANALYSIS OF DATA}

Through repeated viewings of the video material, several themes were identified as recurring in talk in both Norwegian and American school/museum learning settings, hence inviting closer inspection. One such theme that was identified in discussions in both classroom and museum settings centered on the question 'what is art?' As art educators are well aware, the topic 'what makes something art?' is often raised in encounters with modern and contemporary art, particularly by high school students and not infrequently by the educators themselves, as a mean of encouraging aesthetic reflection (Schwartz and Burnette 2004; Samuelsen 2003). Episodes with this theme were thus identified and transcribed, and three of the most interesting 'what is art?' segments were selected for analysis. These three segments will be introduced and presented below. Analysis and discussion will follow the presentation of all three segments.

\section{ART HISTORY IN THE CLASSROOM}

The first segment is from a Norwegian art class that is being introduced to different styles and movements within 'modern art' (all segments are translated from the Norwegian and fictional names are used throughout). The teacher begins her lecture using an overhead projector and a list of different modern art movements. The lecture is based on material from the course textbook and on information provided by the museum they will be visiting. The lights are turned off and slides are shown of works that illustrate concepts and styles representative of abstract and non-objective art.

The teacher provides an art historical account of how some artists sought to break with realistic representation at the turn of the previous century, and she defines abstraction as a general term for works in which traces of figuration may still be apparent. Abstract works of art are then compared and contrasted with another style in modern art, nonobjective art, a genre in which imagery is limited to basic geometric forms and compositions. The students are shown a slide of a Suprematist work by Kasimir Malevich [Fig.1].

Following a brief introduction, the students 
are asked to judge whether Malevich has been successful in conveying the expressed artistic aims. ${ }^{5}$

\section{Segment 1}

1. Teacher: And then moving on to the other side, to Suprematism. And these were concerned with getting away from the random, the incidental. The impressionistic. Later, a later direction. Supra, ah, supra means beyond, away from materiality. That is, they wanted to free themselves from the recognizable figure, we could say, the concrete here and now, but to the concrete beyond. Mmm? Has Malevich, is this what he has done in this painting?

2. Gerard: Is that pastel?

3. Teacher: No, I think it's paint.

4. Teacher: $O K$, the supra material, beyond the material, away from materiality ...

5. Susan: I ... I think you're going to have to do a lot of talking in order for that (nodding at slide) to give me something (laughter).

This exchange may be compared with the next segment from a high school art class in the northeastern part of the United States. The teacher had prepared a lecture and PowerPoint presentation using materials supplied by the museum and the school textbook; she had also downloaded images from the Internet that she wanted to include in her lecture. As in Norway, the first two-hour class was intended to introduce students to terms and concepts in modern art in preparation for their visit to the art museum the following week. In contrast to the segment above, however, the teacher begins the first class by asking students to critically reflect on whether colorfield painting may be considered 'art.' She turns off the lights, projects an image of a color-field painting by Mark Rothko, and distributes a paper handout [Fig.2].

The teacher moves about the classroom and instructs the students, who are sitting at their worktables in the art room, to look at the image and then answer the question on the handout: 'whether or not you think this is art, why or why not?'

\section{Segment 2}

1. Teacher: All right. Who would like to volunteer some of the responses? $O K$, as to whether or not you think this is art or if you don't think it's art. And if you don't volunteer, I'm going to call on random people. Yes (pointing). Tom.

2. Tom: I don't think it's art.

3. Teacher: You don't think it's art? Tom, why would you not think that it's art? (pause) Let's give at least one reason.

4. Tom: It's just a square and rectangle.

5. Teacher: $O K$, so you think the shapes are too simple for it to be art. And you can't recognize the subject matter, you don't know what it is? OK. Yes, Dan.

6. Dan: I think it is art, because it's not just red and yellow, you can see (pointing to slide) right there it gets darker and then it gets lighter...

7. Teacher: $O K$, good, so there's some shading in it, very good, so you see there's some kind of a contrast in there between colors. Yes.

8. Jill: I think art is whatever you want it to be, I mean, a little kid in second grade can draw a picture and it can be art to somebody, it depends on how you look at it, in terms of ...

9. Teacher: Very good, um, art is definitely in the eye of the beholder. You can pretty much 


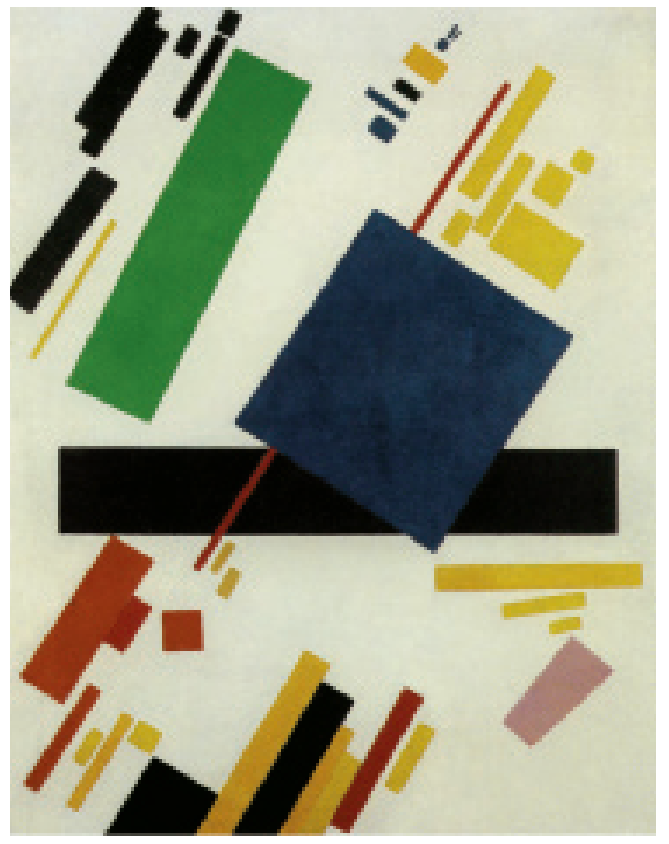

Fig. 1. Kazimir Malevich, Suprematist Construction, 1915-16. Oil on canvas.

(Picture credit: Stedelijk Museum, Amsterdam).

pronounce anything art these days. OK? Do you think this was acceptable back in the day, let's say maybe this artist painted it in, let's just say, in the early 1900s. Do you think this was acceptable?

10. Students: No! (chorus).

11. Teacher: No? Why do you think it was not acceptable?

12. Tom: Because it doesn't mean anything!

13. Rick: Because it wasn't a painting of somebody.

14. Teacher: Because it wasn't a painting of somebody, $O K$, and there was a lot of paintings going on where things had to look like something.

\section{ART HISTORY IN THE MUSEUM}

The final segment is from this same class while on its trip to the museum the following week, when the topic how aesthetic judgments are made' was again raised. Most of the students had been to the museum before, but not in the context of a guided tour of modern and contemporary art. Following activities and discussion in three different galleries, the class moved to a gallery of Duchamp's work. The museum educator (ME) moved about the room, first pointing out Duchamp's representational work while the students sat on the folding chairs they used throughout the tour. She then related the story of Duchamp's Fountain and how he had submitted the uri-

Fig. 2. Mark Rothko, Orange Yellow Orange, 1969 Oil on paper mounted on linen

Picture credit: Marlborogh Gallery, New York.

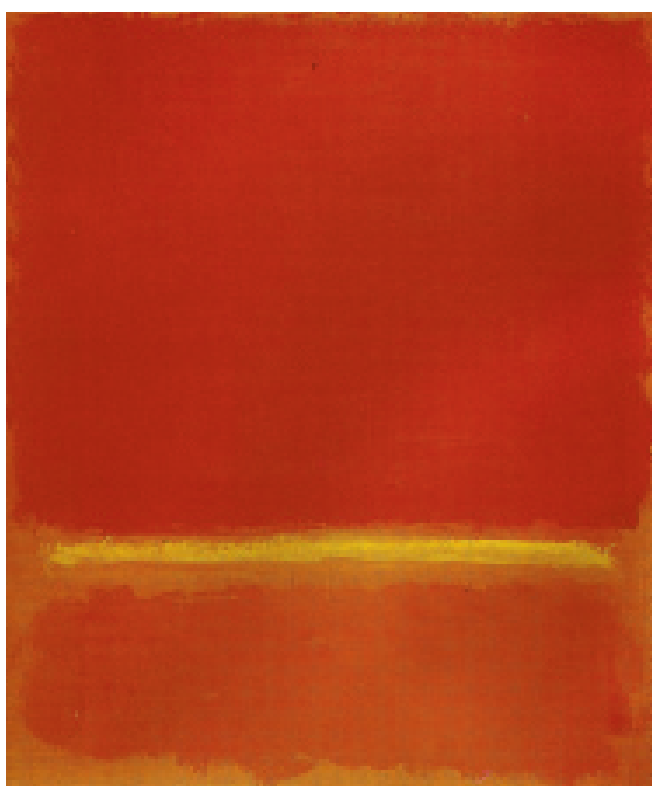


82 nal anonymously for consideration in an exhibition that he and other avant-garde artist friends were curating. The educator explained that Duchamp wanted to test the limits of what would be accepted as art among these radical artists, and there is some discussion about whether the students think it should have been accepted or rejected. This leads to more general talk about the problem of how works become art [Fig.3].

\section{Segment 3}

1. ME: What makes something art? Does a name and a date make something art? What makes something art?

2. Bill: If you took your time to make something.

3. Eva: If you create a feeling.

4. Mark: If it represents something.

5. Jack: Opinion.

6. ME: If you took your time, if you create a feeling. What did you say? If it represents something...

7. Jack: Opinion.

8. ME: Opinion. Whose opinion?

9. Jack: Your opinion.

10. ME: Your opinion as the artist, or your opinion as the viewer?

11. Jack: Both.

12. Mark: As the audience.

13. ME: As the audience? Yeah, who gets to decide what's art?

14. Jack: Basically the public says what's art, but the artist is the one that, I mean no matter what people say, if he's the one still saying in his mind, yeah its art ... so I guess it is the artist who decides.

15. ME: Yeah, so if the artist says it's art but no one else believes that it's art, is it art?

16. Jack: To him.

17. ME: To that person? To the artist? Um, if the museum puts it on the wall, does that mean it's art?

18. Jack: Just means it's popular

\section{ANALYSIS}

In all of the above segments, students look at works of modern art (representations or originals), and discuss concepts according to which the works may be interpreted. In both classroom and museum gallery situations, student responses are mediated by (object) perception, disciplinary knowledge (text), and social interaction. In order to analyze how high school students construct meaning in encounters with modern art, then, concepts are needed that dispense with not only the formal/informal categorical divide, but the distinction text/object as well. In this study, Wertsch's (1998) concepts of mastery and appropriation are useful. ${ }^{6}$

For my purposes, mastery will be associated with the more general activity of 'knowing how to use' such art history terms and conventions as abstract, non-objective, representation, subject matter, modernism, avant-garde, and so on. Appropriation, on the other hand, moves beyond mastery in the sense that a personal stake and motivation is involved in a considered acceptance of the narratives and meanings that are put forth, and is more closely linked with identity than with knowledge (Wertsch 2005). Mastery and appropriation are nonetheless thoroughly intertwined, not unlike Bakhtin's (1986) notion of the dialogical movement between the established, macrolevel conventions of social languages and utterances at the local, microlevel of human interaction.

In the first segment, mastery and appropriation are apparent as two distinct problems for 
the Norwegian students. The teacher compares and links the formal characteristics of the artwork to the aims of certain artists from a distinct period in time (line 1). Susan understands that non-objectivism is a term for a specific genre in modern art history, and that it must be mastered because it is on the curriculum. However, she resists appropriating this genre as 'art' for her. Moreover, she explicitly acknowledges the constitutive role that language, art discourse, plays in appropriating objects as art: "You're going to have to do a lot of talking in order for that to give me something" (line 5). In other words, the students are presented with the challenge of mastering philosophically complex art theories, but have not been involved in any meaning making process that would allow them to appropriate non-figurative painting as art.

Similar comments were made in the parallel Norwegian class, and several students were clearly provoked by the basic, geometric forms in non-objective art, asking the teacher "Is the artist playing a joke on people?" and "What is it the artist is trying to do?" From a sociocultural perspective, these utterances suggest that perception of the image, on its own, is insufficient as mediational means. The process of constructing meaning is understood as one that will be accomplished primarily by talking, not by looking. From a pedagogical perspective, the students may have been more engaged had a dialogue about aesthetic theory prefaced the presentation, in order to develop and encourage critical reflection on what 'art' is, what it has meant in the past, and to make connections with their own culture.

This is precisely what the teacher in the second segment has done when she asks students to explain: "why or why not this work is art?" She supports their reasoning by 'naming' the various concepts in aesthetics that stument with the discourses that have deemed certain works 'art'. This is not an insignificant exercise; in contemporary art education, such articulation is arguably as important as the mastering of art historical styles. ${ }^{7}$ The students initially volunteer aesthetic judgments using criteria that are directly object-related, based on what they see in the image: subject matter ("OK, so you think the shapes are too simple for it to be art. And you can't recognize the subject matter, you don't know what it is?", line 5), and formal qualities ("OK, good, so there's some shading in it, very good, so you see there's some kind of a contrast in there between colors", line 7). In this sense, aesthetic judgments ("I think/don't think it's art because ...") demonstrate a high correlation between levels of mastery and appropriation.

Interestingly, Jill's comment ("I think art is whatever you want it to be", line 8) shifts discussion from how aesthetics makes an art work work (subject matter and formal qualities) to how aesthetics makes an art work art (Paterson 2004). In this sense, this segment also demonstrates the provisional link between aesthetics and art history, and the point made by Peter Osborne that these are "partial and relational disciplines" (2004: 652). The students are also critically reflecting on art and its history - as a social construct when they acknowledge its unstable ontological status: "Why do you think it was not acceptable?" "Because it doesn't mean anything!" "Because it wasn't a painting of somebody" (lines 11-13).

The navigation between mastering and appropriating views on how aesthetic judgments are possible is the topic in segment 3 from the art museum. 'Art' may be judged by quality ("If you took your time to make something", 


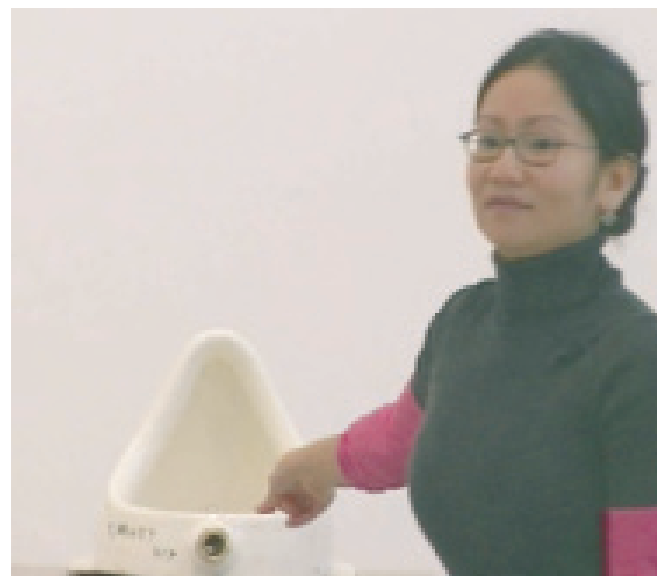

Fig. 3. Museum educator points to Marcel Duchamp's Fountain (1917). Courtesy of Philadelphia Museum of Art.

line 2), its appeal to human emotion ("If you create a feeling", line 3), and its mimetic character ("If it represents something", line 4). These are concepts in aesthetics that the students have mastered. Jack's comment that "opinion" determines art (lines 5-7) also reflects mastery of the teacher's "eye of the beholder" theory from the previous week. However, further reflection is encouraged by the museum educator's follow-up ("Whose opinion?", line 8), and Jack reasons aloud to the conclusion that it must be, in principle, the artist who decides if something is art, even though the audience and the museum may decide in practice (lines 14-18). As long as the artist considers something he made art, it does not matter if no one else believes him (line 15) or if museums exhibit it (line 17). So while Jack masters the concept in contemporary aesthetics that "opinion" determines what is or is not art, he nonetheless rejects this narrative and arrives at a different conclusion, that "it is the artist that decides" (line 14). By assuming such a principled stance, Jack seems to have a personal stake in making this claim as he shifts between a mastered concept of "how aesthetic judgment is possible, in general" ("Opinion", line 7) to the appropriated view of "how aesthetic judgment is possible for me" ("I guess it is the artist who decides", line 14). Through the joint social activity of constructing meaning, art for this student becomes something other than mastering concepts in aesthetics or art history; Jack's appropriated view on art seems to be more about a process of crafting identity. Finally, the very wavering between different positions about how works are judged to be art testifies to the impact of $\mathrm{Du}$ champ's project - i.e. the necessity of articulating the conditions under which aesthetic judgments are made (de Duve 1996).

\section{DISPENSING WITH FORMALITIES}

An analytical and empirical distinction has been made between mastery and appropriation in order to explore at the microlevel of human interaction how high school students jointly construct meaning in encounters with modern art in schools and museums. Social interaction has been the analytical unit in this study rather than characteristics of learning in 'formal' and 'informal' environments. As Rasmussen (2005) points out, operating with an analytical framework that emphasizes the principles and functions of institutions risks obscuring insight into how participants construct knowledge and understanding. This does not mean, however, that institutional features are not apparent in the social interaction. The different learning settings presented above share similar institutional characteristics 
that are apparent as features embedded in activity. The organization of the participation structures is strikingly similar, for example, with both school and museum educators guiding discussion using an initiation, response, feedback (IRF) structure that is commonly used in whole class interaction (Cazden 1988). The management of the physical space, how it both facilitates and prohibits certain use, is also similar for classroom and school field trip settings, as students are seated in a group facing the objects or reproductions while the educators stand and move about. Both classroom teachers and the museum educator are concerned with fostering in students a mastery of disciplinary concepts in art history and aesthetics, and similar semiotic means are used: talking, pointing, texts, images, and the symbolic and physical characteristics of classrooms and museum galleries. In addition, both original works of art and reproductions of artworks assume a primarily (although not solely) instrumental role as mediating tools for art historical and aesthetic concepts.

At the institutional or structural level then, the above data support school field trip research in which formal institutional and social practices from schools are seen as carried across into the museum setting. This perspective allows us to draw such conclusions about principles and the functioning of the respective institutions; the patterns of participation that are produced, motivations, and the types of knowledge and activities that are favored (Paris and Ash 2000; Rasmussen et al. 2003; Rasmussen 2005). However, by examining meaning making processes at the focal level of interaction, we also see that learning about modern art on school field trips and in classrooms is not tidily contained in the concept of formal learning; a compulsory, text-based acti- vity of mastering art historical terminology. Rather, we see that students are deeply engaged in mastering, appropriating - and disappropriating - the social language of contemporary art discourse in museum and schools alike, and that both objects and texts are mediating tools in constructing meaning. In other words, identity, intrinsic motivation, and explanatory engagement are not left at the door just because the environment is characterized as formal. Examining meaning making processes in relation to modern and contemporary art necessitates a break with such traditional distinctions as contextualism/essentialism and formal/informal, text/object, which eclipse the very activity that researchers aim to describe.

Finally, in this study of museum learning as a situated, social activity, we see in small discursive movements a reflection of the larger processes involved in changes in art and its related disciplines. Meaning making is not only a short-term activity that involves change at the individual level - such events become potential knowledge 'objects' for participants across longer timescales and settings. In this sense, a sociocultural approach may bring museum researchers into closer touch with the changing fields of art history, aesthetics, and visual studies. Not unlike art historians, art theoreticians, and art critics, museum researchers should be concerned with closely examining the specific activity through which meaning becomes inscribed into art - what becomes art. Although we may be concerned with different arenas for this activity, art museums will always be among the participants.

\section{ACKNOWLEDGMENTS}

This research was supported by InterMedia, 
86 University of Oslo. I would like to express my appreciation to Prof. Sten Ludvigsen and Assoc. Prof. Andrew Morrison at InterMedia, University of Oslo for their insightful comments and critical readings. I am also thankful to my colleagues in the sociocultural theory research group at InterMedia for many valuable discussions, and to Dr. Andreas Lund and Dr. Ingvill Rasmussen in particular.

\section{ENDNOTES}

1. The generalization essentialism/contextualism acknowledges a broad range of psychological, phenomenological, and sociological theories of seeing and knowing in the disciplines of art history and art theory, the discussion of which exceeds the scope of this article.

2. 'Situated action' is a concept in the social sciences borrowed from ethnomethodology asserting, in the simplest of terms, that the social world is constituted by the local production of meaningful action and not vice versa (Suchman 1987). Discourse and the notion of dialogicality are thus essential to studies of how shared understanding is constructed.

3. "Museums are places of signs, symbols, culturally significant artifacts, tools, and activities. Learning entails meaning making, and it is difficult to think of institutions that more self-consciously value this conceptualization of learning than museums" (Schauble et al. 1998: 4).

4. The excerpts presented in this article are part of a larger corpus of data gathered at one Norwegian art museum, three American art museums, one Norwegian and two American high schools, and one American middle school. The corpus comprises approximately thirty hours of video data that have been analyzed separately, and includes observations from museum tours, museum/school vi- deo conferences, classrooms, and computer rooms. In addition to the core data of video recordings, supplementary data have been used for triangulation purposes; field notes, written assignments, informal interviews with teachers, students, museum educators, curators, and education directors, school textbooks, and museum educational and curatorial material.

5. In his own words, Malevich expressed an intent "to remove the conglomeration of countless things" in representational painting in order to express pure emotion, coining his approach Suprematism: "Under Suprematism I understand the supremacy of pure feeling in creative art" (1959: 67).

6. In brief, mastery is proposed by Wertsch as an alternative means of conceptualizing processes of internalization; mastery is "knowing how" (1998: 50). His concept of appropriation draws on the writings of Bakhtin, and describes a process "of taking something that belongs to others and making it one's own" (1998: 53). The intent of using these concepts is not to make a well-developed distinction between two different kinds of psychological activity. Rather, mastery and appropriation are used to distinguish discursive moves and understanding in junctures of social interaction, the disciplinary domains of art history and aesthetics, and classroom, field trip, and museum gallery situations.

7. As de Duve points out (1996), articulating the conditions for saying this is or is not art has become, since Duchamp, widely accepted as the very definition of aesthetic judgment. In a Vygotskian sense, in articulating their reasons for saying this is or is not art for me, the students may be said to have appropriated aesthetic judgment as a cultural tool. 


\section{REFERENCES}

Allen, S.: "Sociocultural Theory in Museums: Insights and Suggestions". Journal of Museum Education. 22 (2 and 3) 1998: 8-9 .

Bakhtin, M. M.: Speech Genres and Other Late Essays. Trans. V. W. McGee, eds. C. Emerson and M. Holquist. Austin: University of Texas 1986.

Bal, M.: "Visual essentialism and the object of culture". Journal of Visual Culture 2 (1) 2003: 5-32.

Bourriaud, N.: Relational Aesthetics. Les presses du réel. 2002

Cazden, C.: Classroom Discourse: The Language of Teaching and Learning. Portsmouth: Heinemann 1988.

De Duve, T.: Kant after Duchamp. Cambridge: MIT Press 1996.

Dierking, L., K. Ellenbogen, and J. Falk (eds.): "In principle, in practice: perspectives on a decade of museum learning research (1994-2004)". Science Education 88 (1) 2004.

Ellenbogen, K. (ed.): “Sociocultural perspectives on museums". Journal of Museum Education 28 (1) 2003.

Falk, J. H., and L. D. Dierking: "School field trips: assessing their long-term impact”. Curator 40 (3) 1997: 211-217.

Griffin, J. 2004: "Research on students and museums. Looking more closely at the students in school groups". Science Education 88 (1) 2004: 59-70.

Grinder, A. L., and E. S. McCoy: The Good Guide. Scottsdale: Ironwood 1985.

Holly, M. A., and K. Moxey (eds.): Introduction to Art History, Aesthetics, Visual Studies. New Haven: Yale University Press 2002.

Jordan, B., and A. Henderson: "Interaction analysis: foundations and practice". The Journal of the Learning Sciences 4 (1) 1995: 39-103.

Knutson, K.: "Creating a space for learning. Curators, educators, and the implied audience" in $L e$ - arning Conversation in Museums (eds.) G. Lein-

hardt, K. Crowley, and K. Knutson, Mahwah,

NJ: Lawrence Erlbaum 2002.

Leinhardt, G., and K. Knutson: Listening in on Museum Conversations. Walnut Creek: Altamira Press 2004.

Malevich, K.: The Non-Objective World. New York: Paul Theobald 1959.

Martin, L.: "An emerging research framework for studying informal learning and schools". Science Education 88 (1) 2004: 71-82

Mirzoeff, N.: An Introduction to Visual Culture. London: Routledge 1999.

Osborne, P.: "Art beyond aesthetics: philosophical criticism, art history, and contemporary art". Art History 27 (4) 2004: 651-670.

Packer, J., and R. Ballantyne: "Motivational factors and the visitor experience: a comparison of three sites". Curator 45 (3) 2002: 183-198.

Paris, S.: "Situated motivation and informal learning”. Journal of Museum Education 23 (1) 1997: 8-9.

Paris, S., and D. Ash: "Reciprocal theory building inside and outside museums". Curator 43 (3) 2000: 199-210.

Paris, S., and S. Hapgood: "Children Learning with Objects in Informal Learning Environments" in Perspectives on Object-Centered Learning in Museums, ed. S. Paris, Mahwah: Lawrence Erlbaum 2002.

Paterson, D.: "Everything in its right place: Foucault and the "Ideology of the Aesthetic'". Postgraduate Journal of Aesthetics 1 (3) 2004: 111-123.

http://www.british-aesthetics.org/Home.aspx?tabin$\mathrm{dex}=6 \&$ tabid $=63$

Pierroux, P. (in press): "Vygotsky and metamorphism: situating critical thinking”. Inquiry. An Interdisciplinary Journal of Philosophy.

Popketwitz, T. S.: "Dewey, Vygotsky, and the social administration of the individual: constructivist pedagogy as systems of ideas in historical spaces". 
American Educational Research Journal 35 (4) 1998: 535-570.

Rasmussen, I.: Project work and ICT: studying learning as participation trajectories. Unpublished doctoral thesis. University of Oslo 2005.

Samuelsen, A. M.: Kunstformidling for barn $i$ kunstmuseum og skole - med vekt på formidlerrollen (Art education for children in art museum and school - with focus on the museum educator). Unpublished PhD thesis, University of Bergen 2003.

Schauble, L., G. Leinhardt, and L. Martin: "A framework for organizing a cumulative research agenda in informal learning contexts". Journal of $M u$ seum Education. 22 (2 and 3)1998: 3-7.

Schwartz, B., and A. Burnette: "Making Web Sites for Young Audiences". Conference Paper: $M u$ seums on the Web. Arlington: Archives \& Informatics 2004.

Suchman, L. A.: Plans and Situated Actions. Cambridge: Cambridge University Press 1987.
Vygotsky, L. S.: Mind in Society. Cambridge: Harvard University Press 1978.

Wertsch, J. V.: Mind as Action. New York: Oxford University Press 1998.

Wertsch, J. V.: Mastery and Appropriation. Lecture at University of Oslo, August 17, 2005.

Xanthoudaki, M.: "Is it always worth the trip? The contribution of museum of gallery educational programmes to classroom art education". Cambridge Journal of Education 28 (2) 1998: 181-195.

Palmyre Pierroux, Research Fellow. InterMedia, University of Oslo.

E-mail:palmyre@intermedia.uio.no 